\title{
TECIDO ACROBÁTICO: PROPOSTA DE CRIAÇÃO DE E-BOOK SOBRE FORTALECIMENTO MUSCULAR
}

\author{
Vania Loureiro*, Marco Carlos Uchida
}

\begin{abstract}
Resumo
Em função da escassez de estudos relacionados com o tecido acrobático este projeto visa colaborar com professores e praticantes da modalidade. O e-book possui cinco capítulos. O primeiro é uma introdução, contendo a história do tecido acrobático no mundo e no Brasil, no que consiste a modalidade, como ela está no Brasil nos dias atuais e onde e por quem é praticado. O segundo capítulo é uma breve revisão de cinesiologia. O terceiro, fala sobre os movimentos de subidas no tecido. Contém a descrição e análise cinesiológica das subidas simples e russa. No quarto, está a descrição e análise cinesiológica da chave de cintura e trava de curva e o movimento de enrolar as pernas. E no quinto capítulo está presente a prescrição de exercícios de fortalecimento muscular. Com o estudo foi possível adquirir conhecimento de cinesiologia e treinamento, aplicando a prática de tecido acrobático, além de disponibilizá-lo para todos os interessados, atendendo a uma lacuna existente na literatura.
\end{abstract}

Palavras-chave: Ginástica, Força, Cinesiologia

\section{Introdução}

O praticante do tecido acrobático tem por objetivo subir neste tecido, que costuma ser do tipo liganete, até uma altura desejada e a partir de travas fazem posições que chamamos de figuras, ou quedas, onde os participantes perdem altura e param bruscamente (BORTOLETO e CALÇA, 2007). A realização da prática exige o desenvolvimento de habilidades físicas específicas aos seus participantes como força, flexibilidade e coordenação motora (SOARES e BORTOLETO, 2011). De acordo com Cardani (2016), a quantidade de praticantes de atividades circenses é crescente o que mostra a necessidade de estudos que possam ser utilizados pelos profissionais que atuam na área, visto que são escassos os que falam sobre tecido acrobático e fortalecimento para prevenção de lesões, pelo nosso conhecimento. Pensando nisso, o objetivo desse projeto é gerar um e-book, contendo análise cinesiológica dos exercícios do tecido acrobático que são base para vários outros e uma proposta de fortalecimento muscular, que então será disponibilizado de forma eletrônica e gratuita.

\section{Resultados e Discussão}

O projeto iniciou com a busca por referências bibliográficas nas bases de dados Pubmed, Scielo, Google acadêmico e nas bibliotecas da Unicamp. Porém, apenas nesse penúltimo, foi encontrado material específico, mas nada relacionado com exercícios, fortalecimento ou prevenção de lesões. Alguns deles foram utilizados para a construção da introdução. O capítulo Cinesiologia conta com uma breve explicação sobre alguns termos, os segmentos do corpo e os músculos responsáveis pelos movimentos das articulações com o nome dos movimentos.

Nos capítulos que falam sobre as subidas e as travas, existem fotos dos movimentos, explicações passo a passo e análises cinesiológicas de cada movimento. Essas análises foram expressas na forma de tabelas com as articulações e os músculos responsáveis pelos movimentos durante a realização dos movimentos no tecido acrobático. Os dois capítulos totalizam trinta e três fotos e quinze tabelas.

As fotos foram feitas em um estúdio que oferece aulas de tecido acrobático na cidade de Americana-SP chamado MOOV. Foi colocado um fundo de pano preto na parede, colchonetes pretos no chão e pendurado um tecido branco, que contrastava com o macacão vermelho, pensando em facilitar a visualização nas fotos. Foram fotografados o passo a passo dos movimentos subida simples, subida russa, chave de cintura, enrolar as pernas e trava de curva.

No quinto capítulo, está presente uma proposta de fortalecimento muscular, com alguns exercícios para os grupos musculares mais exigidos.

\section{Conclusões}

Foi de grande importância o entendimento e a aplicação da cinesiologia e do treinamento de força, nesse caso, aplicados ao tecido acrobático, além de futuramente disponibilizar gratuitamente o e-book. Com o desenvolvimento desse trabalho foi possível atender a uma lacuna existente na literatura de apoio para os praticantes de tecido acrobático e seus interessados.

\section{Agradecimentos}

Agradeço a toda ajuda e atenção do meu orientador Prof. Marco C. Uchida, ao estúdio Moov pelo empréstimo do espaço para a realização das fotos e ao CNPq pela concessão da Bolsa de Pesquisa.

BORTOLETO, Marco Antonio Coelho; CALÇA, Daniela Helena. O TECIDO CIRCENSE: FUNDAMENTOS PARA UMA PEDAGOGIA DAS ATIVIDADES CIRCENSES AÉREAS. 2007. Disponível em: <https://periodicos.sbu.unicamp.br〉. Acesso em: 27 ago. 2018.

CARDANI, Leonora Tanasovici. O ENSINO DAS ATIVIDADES CIRCENSES NAS ESCOLAS MUNICIPAIS DE CAMPINAS-SP. 2016. Disponível em: $<$ http://www.bibliotecadigital.unicamp.br>. Acesso em: 19 out. 2016.

LIPPERT, Lynn S. Cinesiologia Clínica e Anatomia. 5. ed. Philadelphia: Guanabara Koogan Ltda, 2011. 339 p.

SOARES, Daniela Bento; BORTOLETO, Marco Antonio Coelho. A PRÁTICA DO TECIDO CIRCENSE NAS ACADEMIAS DE GINÁSTICA DA CIDADE DE CAMPINAS-SP: O ALUNO, O PROFESSOR E O PROPRIETÁRIO. 2011. Disponível em: 〈http://periodicoscientificos.ufmt.br〉. Acesso em: 27 ago. 2018. 